\title{
CONTROLE SOCIAL DEMOCRÁTICO: O PAPEL (OU A CONTRIBUIÇÃO) DOS ASSISTENTES SOCIAIS NO CMAS/RJ
}

\section{RESUMO}

Este trabalho destaca algumas reflexões acerca do papel dos assistentes sociais no exercício do controle social, no Conselho Municipal de Assistência Social (CMAS) da cidade do Rio de Janeiro. Abordam-se aspectos relevantes mapeados a partir da realidade do CMAS/RJ, bem como o entendimento do papel desses profissionais neste espaço de controle. Entende-se que, atualmente, os assistentes sociais são chamados a ocupar novos espaços de trabalho, como os dos conselhos de políticas e de direitos. Esse fenômeno se deve à inserção privilegiada do Serviço Social no âmbito das políticas sociais, em sua execução, planejamento, gestão, monitoramente, avaliação, bem como reconhecimento dos conselhos como espaços sócio-ocupacionais do assistente social.

Palavras-chave: Assistência Social, Profissional, Conselho de Assistência, Controle Social.

\section{INTRODUÇÃO}

A Constituição Federal de 1988 traz uma nova concepção para a Assistência Social brasileira. Incluída no âmbito da Seguridade Social e regulamentada pela Lei Orgânica da Assistência Social ${ }^{1}$ (LOAS), em dezembro de 1993, lei alterada pela N 12.435 de 2011, como política social pública, a assistência social inicia seu trânsito para um campo novo: o campo dos direitos, da universalização dos acessos e da responsabilidade estatal. Também institui diversos mecanismos e formas de participação social, como conselhos, conferências, ouvidorias, processos de participação no ciclo de planejamento e orçamento público, audiências e consultas públicas, mesas de diálogo e negociação, entre outros. Atualmente, surge a proposta da Política Nacional de Participação Social que visa consolidar estes avanços. Pode-se afirmar que a participação social constitui uma realidade.

Nos últimos anos, foram criados novos espaços e mecanismos de viabilização do controle democrático ${ }^{2}$, os quais estão na interface sociedade civil-Estado e visam a ampliação da participação popular na formulação das políticas sociais e na distribuição de recursos. Assim, os conselhos são espaços de controle, em especial, de fundos, recursos públicos e políticas sociais.

Estas ações demonstram avanços e apontam desafios, no que tange a área da participação social, a qual não foi empírica e politicamente avaliada. Em especial, sobre

\footnotetext{
${ }_{2}^{1}$ A Lei Orgânica da Assistência Social, LOAS, foi alterada pela Lei Federal n 12.435/2011.

2 Controle democrático é uma categoria utilizada por PEREIRA, Potyara Amazoneida. Centralidade e exclusão social: duplo entrave à Política de Assistência Social. In: Revista Ser Social. $n^{\circ} 3$. Brasília:UnB, julho à dezembro de 1998. Pereira afirma que prefere essa categoria à de controle social, pois esta última remete ao contexto histórico brasileiro de controle do Estado sobre a sociedade.
} 


\section{SEMINÁRIO DE PESQUISA EM CIÊNCIAS HUMANAS - SEPECH \\ Humanidades, Estado e desafios didático-científicos \\ Londrina, 27 a 29 de julho de 2016}

a prática profissional do assistente social no exercício do controle democrático da Política de Assistência Social.

Entende-se que os assistentes sociais são chamados a ocupar novos espaços de trabalho, como os dos conselhos de políticas e direitos. Esse fenômeno se deve à inserção privilegiada do Serviço Social no âmbito das políticas sociais, em sua execução, planejamento, gestão, monitoramente, avaliação, bem como reconhecimento dos conselhos como espaços sócio-ocupacionais do assistente social. Como ressalta o artigo $4^{\circ}$ da Lei 8.662 de 1993 sobre as competências do Assistente Social no que se refere ao papel desses profissionais nos espaços de controle democrático.

I - elaborar, implementar, executar e avaliar políticas sociais junto a órgãos da administração pública, direta ou indireta, empresas, entidades e organizações populares;

II - elaborar, coordenar, executar e avaliar planos, programas e projetos que sejam do âmbito de atuação do Serviço Social com participação da sociedade civil;

VII - planejar, executar e avaliar pesquisas que possam contribuir para a análise da realidade social e para subsidiar ações profissionais;

IX - prestar assessoria e apoio aos movimentos sociais em matéria relacionada às políticas sociais, no exercício e na defesa dos direitos civis, políticos e sociais da coletividade;

Este artigo destaca algumas reflexões acerca do papel dos assistentes sociais, conselheiros, representantes governamentais e da sociedade civil, no exercício do controle democrático, no Conselho Municipal de Assistência Social (CMAS). Abordam-se aspectos relevantes, mapeados da realidade do CMAS/RJ, bem como o entendimento do papel desses profissionais nesse espaço laboral.

\section{O CENÁRIO POLÍTICO BRASILEIRO ANOS 80 E 90: ALGUNS APONTAMENTOS}

A Constituição Federal de 1988 ressalta a participação popular como uma das condições essenciais da descentralização político-administrativa, possibilitando a abertura de espaços para a participação da sociedade civil na realização do controle democrático das políticas sociais, que passam a ser reconhecidas como dever do Estado e direito dos cidadãos.

É nesse período que os movimentos sociais e organizações se lançam na luta pela redemocratização da sociedade e do Estado; é um marco para a democracia brasileira, na qual o cidadão passa a ter o direito de, perante a administração pública, opinar sobre as prioridades, participar, decidir, compartilhar, validar e proteger a aplicação dos recursos públicos na geração de benefícios à sociedade.

A participação social se institucionaliza no processo de democratização do país, incluindo-se no arcabouço jurídico-legal do Estado e interferindo nas estruturas de representação da sociedade. 


\section{SEMINÁRIO DE PESQUISA EM CIÊNCIAS HUMANAS - SEPECH \\ Humanidades, Estado e desafios didático-científicos \\ Londrina, 27 a 29 de julho de 2016}

Em seu estudo, Dagnino (1994) observa que, a partir dos anos 90, surge uma nova noção de cidadania, a qual está intrinsecamente ligada à experiência concreta dos movimentos sociais. Segundo a autora, a organização desses movimentos aliada à luta por direitos - tanto de igualdade como da diferença - constituiu a base de uma nova noção de cidadania e, sobretudo, a construção e difusão de uma cultura democrática contributiva à criação de um espaço público onde os interesses comuns e os particulares, as especificidades e diferenças podem ser discutidas. Um exemplo foi o que ocorreu tanto no âmbito dos Conselhos Populares dos bairros, como na discussão mais ampla no Fórum do Orçamento Participativo de Porto Alegre.

É nesse contexto histórico que os conselhos de políticas e de direitos emergiram pautados pelos princípios da democracia participativa e deliberativa, como um dos mecanismos de participação da sociedade civil no controle democrático das políticas sociais.

Não é demais reafirmar que o controle democrático no Brasil tem seu grande marco estabelecido pela Constituição Federal de 1988, que se pautou pelos princípios da descentralização e da participação popular, instituindo instrumentos para que a sociedade pudesse exercer o seu papel fiscalizador das ações do Estado na busca do bem e do interesse comum.

O Sistema Único de Assistência Social (SUAS): busca por maior transparência e participação como exigência em nível nacional

Com a implementação da Política Nacional de Assistência Social (PNAS), em 2004, são pautados os princípios da universalização do acesso, da descentralização políticoadministrativa das decisões e ações e, principalmente, do reforço à participação organizada de amplos segmentos da sociedade.

$\mathrm{Na}$ lógica do SUAS, os espaços privilegiados de efetivação da participação da sociedade civil são os conselhos e as conferências, convocadas ordinariamente a cada quatro anos, os quais têm a atribuição de avaliar a situação da assistência social e propor diretrizes para o seu aperfeiçoamento. Cabe aos conselhos, segundo o Artigo 18, da LOAS, a atribuição de: a) fiscalizar a execução da política da Assistência Social e de seu financiamento, em consonância com as diretrizes propostas pela conferência; b) aprovar o plano; c) apreciar e aprovar a proposta orçamentária para a área; d) o plano de aplicação do fundo, com a definição dos critérios de partilha dos recursos, exercidos em cada instância em que estão estabelecidos. Os conselhos também normatizam, disciplinam, acompanham, avaliam e fiscalizam os serviços de assistência social, prestados pela rede socioassistencial, definindo os padrões de qualidade de atendimento e estabelecendo os critérios para o repasse de recursos financeiros.

Assim, os conselhos de assistência social são definidos como locus de construção de uma esfera pública democrática, como estratégia de publicização, onde desprivatizar a ação do Estado significa a construção de espaços públicos de negociação dos interesses distintos presentes na sociedade.

Torna-se claro, contudo, que essa perspectiva de mudança no domínio da cultura política enfrenta resistência dos grupos sociais que secularmente se apropriaram do patrimônio público. Por isso mesmo, as formas como a assistência social, a participação e a representatividade são compreendidas e assumidas pelos conselheiros na sua prática 


\section{SEMINÁRIO DE PESQUISA EM CIÊNCIAS HUMANAS - SEPECH \\ Humanidades, Estado e desafios didático-científicos \\ Londrina, 27 a 29 de julho de 2016}

cotidiana e poderão ou não definir o conselho como espaço de construção da democracia e de socialização da política. Isto ocorre porque, no plano normativo, os conselhos de assistência social se configuram como um espaço legítimo de participação da população, devendo expressar os interesses da coletividade. Contudo, dependendo dos atores sociais que compõem cada conselho, da correlação de forças no seu interior e da relação que estabelece com o governo local, esse também pode tornar-se alvo de cooptações e manipulações. É salutar frisar que:

\footnotetext{
"No Brasil, o estilo político tradicional é de resolver as situações caso a caso e, de preferência, no interior dos gabinetes, e não de forma clara, global, transparente e pública (...) se o assunto é decidido em petit comité entre os mesmos, como pode ocorrer a vigilância do controle social? (...) o espaço do controle social, ainda que institucionalizado, não é meramente administrativo, é um espaço político que põe em cena interesses, imaginários, representações (...) não se pode ser conivente com a transformação do espaço do controle social em uma continuidade burocrática de reuniões, onde não se tem o compromisso com os resultados e efeitos" (SPOSATI \& LOBO, 1992: 371, 372, 373, 377).
}

Na visão de Raichelis (2011), a implantação dos conselhos de assistência social pode significar um impulso na publicização dessa política, na medida em que incorpore os mecanismos publicizadores: visibilidade social, controle democrático, representação de interesses coletivos e democratização.

Além disso, o controle democrático não pode ser entendido como mera fiscalização e denúncia, pois ele só existe na medida em que haja informação, conhecimento, argumentação competente e consequente dos atores envolvidos nas disputas políticas. Portanto, implicam negociação, pactuação, construção de alianças, acordos, diálogos e interfaces.

Constata-se que a atuação dos conselhos de assistência social representa avanços e recuos na mobilização de setores populares, principalmente no que se refere a sua representação, o que não difere da realidade da cidade do Rio de Janeiro.

\section{CONSELHO DE ASSISTÊNCIA SOCIAL E O EXERCICIO PROFISSIONAL DO ASSISTENTE SOCIAL}

\subsection{O Conselho Municipal de Assistência do Rio de Janeiro (CMAS/RJ)}

O CMAS/RJ foi criado pela Lei Municipal no 2.469, de 30 de agosto de 1996. É um órgão com funções deliberativas, fiscalizadoras, de caráter permanente e composição paritária entre o governo e a sociedade civil, vinculado à estrutura da administração pública municipal. Sua organização, composição e competência são fixadas em lei, possibilitando a gestão democrática da política de assistência social e o exercício do controle democrático. Tem estrutura definida pelo Decreto $n^{\circ} 25.591$, de 26 de julho de 2005 e pelo seu Regimento Interno.

A organização do CMAS/RJ prevê, para desenvolvimento de suas ações, a constituição de Assembleia Ordinária e/ou Extraordinária, duas Câmaras de Inscrição de Processos, 


\section{SEMINÁRIO DE PESQUISA EM CIÊNCIAS HUMANAS - SEPECH \\ Humanidades, Estado e desafios didático-científicos \\ Londrina, 27 a 29 de julho de 2016}

Mesa Diretora, Secretaria Executiva e Comissões Temáticas - estruturas permanentes. O referido Conselho possui cinco comissões temáticas, a saber: a) Norma de Assistência Social; b) Política de Assistência Social; c) Orçamento e Finanças da Assistência Social; d) Administração do Fundo Municipal de Assistência Social e e) Comissão Permanente de Apuração de Denúncias. A Mesa Diretora do CMAS é constituída por: Presidente, Vice-Presidente, Primeiro(a) Secretário(a), Segundo(a) Secretário(a) e Coordenadores das Comissões Temáticas.

O Conselho é composto pela Secretária Executiva, que é a agente que acompanha e controla o cotidiano institucional do Conselho. Trata-se de um cargo de chefia, nomeada pelo Gestor Municipal; além de uma assessor adjunto da secretaria executiva, o Conselho possui três assistentes sociais, além de três agentes administrativos que são recursos humanos importantes para o desenvolvimento do controle social, oferecendo suporte técnico e administrativo na manutenção do dia a dia do Conselho. A Secretária Executiva é, portanto, a gerente técnica possuindo um relevante papel de assessoria e também de organização das rotinas das atividades realizadas pelos conselheiros e pelos profissionais a ela vinculados. Cabe esclarecer que o CMAS/RJ é composto por uma equipe técnica com sete profissionais dentre eles, 1 psicológico, 3 assistentes sociais, 3 administrativos.

O CMAS/RJ é composto de forma paritária por 40 membros, entre titulares e suplentes, tendo como representantes da sociedade civil - entidades prestadoras de serviços, assessoramento e defesa de direitos; entidades de organização de usuários e entidades de trabalhadores na área de assistência social.

A maioria das Secretarias Municipais indicam para compor o CMAS/RJ assistentes sociais (representantes da pasta responsável pela política de assistência social, saúde, habitação, educação, entre outros) e número significativo de representantes da sociedade civil - também assistentes sociais. Assim, a rede socioassistencial privada e as secretarias municipais têm por hábito a indicação de assistentes sociais para compor o referido Conselho, talvez por entendimento de que essa categoria domine o tema.

Não há dúvidas que as alianças da sociedade civil com a representação governamental são um elemento fundamental para o estabelecimento de consensos. Como prevê a PNAS (2004), os conselhos paritários, no campo da assistência social, têm como representação da sociedade civil, os usuários ou organizações de usuários, entidades e organizações de assistência social (instituições de defesa de direitos e prestadoras de serviços), trabalhadores do setor (Artigo 17 - 11).

Um dos aspectos fundamentais para a legitimidade da política de assistência social está na participação dos cidadãos, através da sociedade civil organizada. Desta forma, buscase a ruptura com a tendência histórica de segundo plano da sociedade civil perante o Estado, o fortalecimento das formas democráticas de relação entre as esferas estatal e privada.

É importante assinalar que, cada conselheiro eleito para representar um segmento, estará não só representando sua categoria, mas a política como um todo em sua instância de governo.

Cabe destacar que as constantes avaliações dos processos de implantação da Assistência Social, como direito dos que dela necessitarem e dever do Estado, vêm colocando em evidência dificuldades e limites para construção dessa política pública quer no nível federal, estadual ou municipal. Um deles circunscreve-se na desconstrução da noção, 


\section{SEMINÁRIO DE PESQUISA EM CIÊNCIAS HUMANAS - SEPECH \\ Humanidades, Estado e desafios didático-científicos \\ Londrina, 27 a 29 de julho de 2016}

presente em boa parte das instituições, de que a política de assistência social pode ser equiparada à caridade e à benemerência.

\subsection{A atuação profissional dos assistentes sociais no CMAS/RJ}

A criação do Conselho Municipal de Assistência Social atendeu ao novo desenho institucional brasileiro, que projetou sua ênfase na descentralização administrativa, atribuindo novas responsabilidades ao executivo municipal que alterou a organização das ações socioassistenciais nos municípios e contribuiu para maior participação da sociedade no acompanhamento da execução da Política de Assistência Social. Cabe lembrar que os municípios foram convocados a construir seus conselhos a partir de iniciativas local e autônoma (confirmadas por lei municipal).

É nesse contexto histórico que os Conselhos de Assistência Social emergiram pautados pelos princípios da democracia participativa e deliberativa, entendendo-se como um dos mecanismos de participação da sociedade no controle democrático das políticas sociais, ou seja, institucionalizando a participação da sociedade na tomada de decisões e fiscalização das políticas públicas nas mais diversas áreas sociais.

Raichelis (2011) observa que o controle democrático é peça-chave na constituição do espaço público e que os Conselhos de Assistência Social são entendidos como canais importantes de participação coletiva e de criação de novas relações políticas entre governos e cidadãos e, sobretudo, de construção de um processo continuado de interlocução pública.

No entanto, esse elemento de controle democrático, pensado na perspectiva da democracia participativa, convive com tendências típicas da tecnocracia e do clientelismo que embaçam a consolidação de uma cultura política democrática na Assistência Social.

Segundo essa linha de pensamento, alguns autores como Oliveira (2003), a Assistência Social é um campo político em que, de um lado favorece a transição para um modelo participativo, e, de outro, impede sua consolidação, na medida em que mantêm atitudes e práticas perpetuadoras de fragilidades dos mecanismos de mediação política.

Em seus estudos, Oliveira (2003) resgata o entrave constituído pela matriz conservadora, enraizada no favor, no mando e no apadriamento, baseada na reciprocidade e em relações de caráter personalizado, para a construção da nova Assistência Social brasileira. Ao analisar a ação dos gestores de Assistência Social em Santa Catarina, Oliveira transita entre o marco da democracia, da tecnocracia, do patrimonialismo e do clientelismo. Sua hipótese é que a cultura política enraizada no campo da Assistência Social funciona como um dos entraves para a sua construção como política democrática e participativa.

Segundo a autora, essa cultura política, especialmente no caso da Assistência Social, vem sendo construída ao longo de um percurso histórico marcado pelo embate entre posições políticas e ideológicas conflitantes, que a definem, sob a lógica do favor, em 


\section{SEMINÁRIO DE PESQUISA EM CIÊNCIAS HUMANAS - SEPECH \\ Humanidades, Estado e desafios didático-científicos \\ Londrina, 27 a 29 de julho de 2016}

detrimento de sua confirmação sob a ótica do direito; portanto, uma Cultura Política enraizada na identificação com o assistencialismo e a filantropia.

Assim, o Conselho de Assistência Social é um espaço complexo, conflituoso e contraditório, onde as negociações e os embates são permanentes. Esses espaços ainda revelam uma situação paradoxal de participação, controle social e também corrupção e clientelismo. Na maioria das vezes, os conselhos atuam mais no papel de fiscalizador do que de elaborador de políticas.

Nesse sentido, as ações da sociedade e, em especial, dos assistentes sociais em torno do controle das políticas sociais têm enfrentando desafios permanentes com o compromisso da garantia do controle e dos direitos sociais.

Não há dúvidas de que a criação do Conselho de Assistência Social estimulou maior participação da sociedade na organização e gestão da política no âmbito local. Por outro lado, exigiu uma sociedade capaz de defender seus interesses e incluí-los na agenda das políticas públicas. O exercício do controle social é uma prática que conjuga tanto a questão técnica quanto a política e que marca a representação dos assistentes sociais nos Conselhos Municipais e, consequentemente, o modo como este segmento impulsionou a agenda pública em torno do controle democrático.

A descentralização e a municipalização das políticas públicas vêm ampliando o mercado de trabalho para os assistentes sociais. Com isso abrem-se novos canais para atuação profissional, que não se restringem apenas à execução, mas também à formulação e gestão das políticas sociais.

Uma autora que elucida tal discussão é Iamamoto (2010), a qual destaca que a inserção do assistente social junto às políticas de proteção social refere-se à particularidade interventiva do profissional em lidar cotidianamente com as múltiplas e diversificadas expressões da questão social, enfatizando a autora a aptidão do profissional em responder às novas e às antigas atribuições.

Dos estudos que analisam a atuação dos assistentes sociais nos espaços de deliberação das políticas sociais, encontramos posições diferentes e pouco analíticas. De um lado, há o debate que afirma que os assistentes sociais contribuem, mesmo que de forma ainda reduzida, ao controle democrático das políticas sociais (Bravo; Souza, 2002). De outro lado, existem estudos nos quais a inserção dos assistentes sociais ainda não está disseminada nos Conselhos, apesar da expansão do controle democrático das políticas públicas e das diversas possibilidades de sua participação nesses espaços, a partir da Constituição de 1988.

Também é importante elucidar que a análise da participação do assistente social no Conselho Municipal de Assistência Social leva em conta os pilares éticos, teóricometodologico e sócio-históricos que fundamentam a direção sociopolítica do Serviço Social na atualidade.

Em nossos levantamentos sobre a atuação de assistentes sociais no CMAS/RJ, identificou-se que $50 \%$ dos conselheiros são assistentes sociais, seguido pelos 


\section{SEMINÁRIO DE PESQUISA EM CIÊNCIAS HUMANAS - SEPECH \\ Humanidades, Estado e desafios didático-científicos \\ Londrina, 27 a 29 de julho de 2016}

psicólogos e pedagogos; quase a totalidade de conselheiros possui nível superior e os assessores técnicos são assistentes sociais, inclusive a secretária executiva.

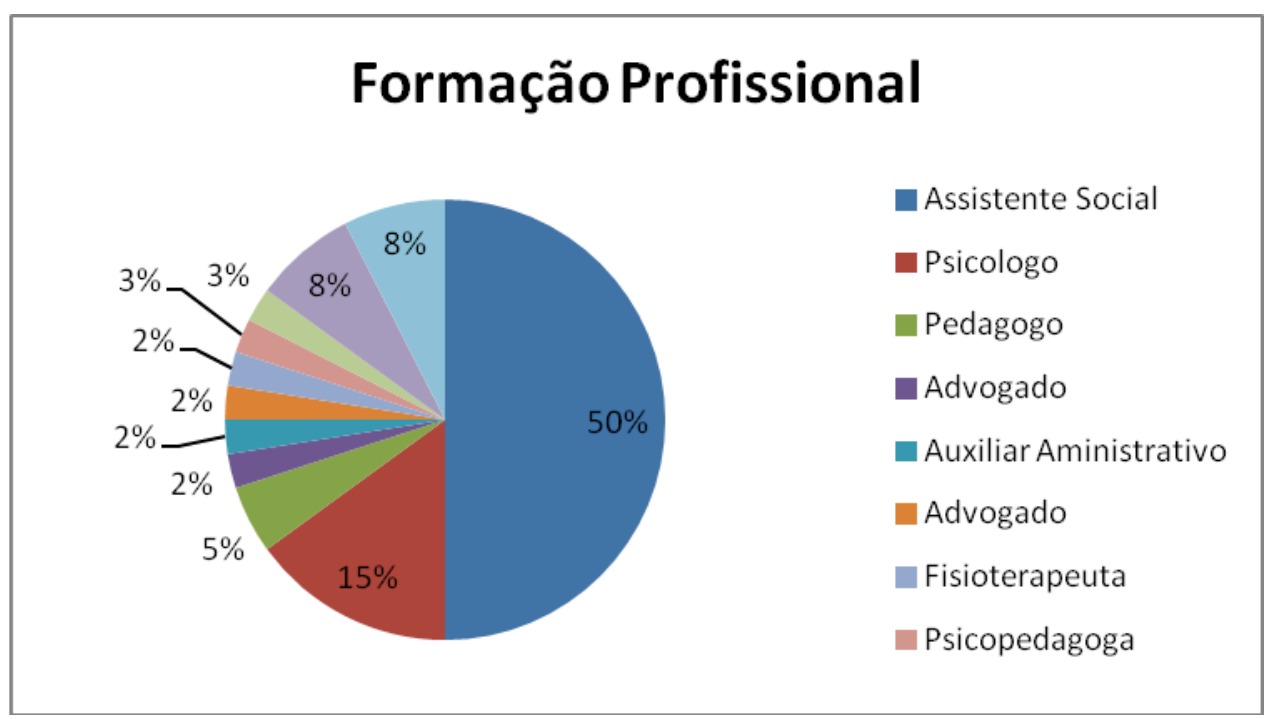

Fonte: CMAS/RJ - Perfil profissional dos Conselheiros Gestão 2015-2017

\section{CONSIDERAÇÕES FINAIS}

No momento de criação dos conselhos, um dos objetivos da sociedade civil organizada foi o de institucionalizar a participação na tomada de decisões e fiscalização de políticas públicas nas mais diversas áreas sociais - o que ganha dimensão e complexidade mais densa nas metrópoles, em função das questões deste debate, além da distância territorial a ser acompanhada/fiscalizada, somada ao número expressivo de participantes envolvidos (usuários, trabalhadores, gestores).

Os conselhos não são percebidos como canais de expressão porque são muito burocratizados. Genro adverte que “(...) enganam-se aqueles que pensam que o espaço do conselho é um marco neutro, pelo fato de ali estarem representados todos os setores e ideologias da sociedade" (2003: 35).

Muitas vezes os conselheiros são representantes de si próprios e, portanto, fáceis de serem cooptados, o que somado à desmobilização em função da relação convenial, emperra o processo de controle social qualificado. Esses espaços ainda revelam uma situação paradoxal de participação, controle social e também corrupção e clientelismo. Boa parte dos conselhos atua mais na fiscalização do que na elaboração de políticas.

A política de assistência social traz arraigada em si características históricas, impasses para a materialização da assistência social como política pública. Dentre estas, destacam-se: a) pouca publicização da política de assistência social; b) fragilidade da participação dos conselheiros; c) manutenção do caráter caritativo das ações e d) burocratismo - desafios postos no processo de construção de um controle democrático e que envolvem diferentes profissionais, com destaque para os(as) assistentes sociais. Também, é preciso reconhecer que há uma dialética, um conflito, uma tensão permanente entre Estado e sociedade civil. Não é demasiado lembrar que o SUAS foi construído nessa dialética Estado-sociedade civil, demonstrando a importância e a 


\section{SEMINÁRIO DE PESQUISA EM CIÊNCIAS HUMANAS - SEPECH \\ Humanidades, Estado e desafios didático-científicos \\ Londrina, 27 a 29 de julho de 2016}

necessidade indispensável de diálogo, de permanente interlocução, em que a atuação de assistentes sociais, especificamente na realidade analisada, faz toda a diferença.

O exercício do controle democrático é uma prática que conjuga tanto questão técnica quanto política. Nesse sentido, é imprescindível a apropriação por parte dos conselheiros de conhecimento sobre a Política de Assistência Social e o Sistema Universal de Assistência Social - SUAS, em todas as suas dimensões e especificidades. Historicamente, a assistência social constitui-se em um universo heterogêneo de ações dispersas e descontínuas de órgãos governamentais e instituições privadas, que se configura num espaço multifacetado de práticas sociais. Essa realidade se reflete na fragilidade da participação dos conselheiros e da rede na deliberação e execução da política de assistência social.

Ainda há muito a percorrer. Mesmo que os Conselhos de Assistência Social não sejam responsáveis pela gestão, os conselheiros têm a responsabilidade de saber como funcionam a elaboração, aprovação e a execução do orçamento para que possam fiscalizar se o poder local está realizando a gestão dos recursos de forma correta. Talvez, resida ai, o fato da apropriação desse espaço pelo profisisonal da Assistência Social. Entende-se que estes profissionais estão instrumentalizados no entendimento das peças orçamentárias - como, por exemplo, o Plano Plurianual e a Lei de Diretrizes Oçarmentárias para que se possa de forma efetiva fiscalizar a execução da Política na localidade. Certamente, este é um dos maiores desafios contemporaneos enfretados pelos profissionais da assistência social que desempenham funções nos espaços de controle social democrático.

\section{REFERÊNCIAS}

ABREU, M. M. Serviço Social e a organização da cultura: perfis pedagógicos da prática profissional. São Paulo: Cortez, 2002.

BRASIL. Constituição da República Federativa do Brasil, 1988.

BRASIL, MDS. Fotografia da Assistência Social no Brasil na perspectiva do SUAS. Indicadores da Gestão Municipal da Política de Assistência Social no Brasil (2005/2006), dezembro de 2007.

Assistência Social, 2004.

Política Nacional de Assistência Social. Brasília, Secretaria de

BRASIL, Presidência da República. Lei Orgânica de Assistência Social, n. 8.742, de 7 de dezembro de 1993.

DAGNINO, E. (org.). Anos 90: política e sociedade no Brasil. São Paulo: Brasiliense, 1994. Apresentação (p. 7- 15) e Os movimentos sociais e a emergência de uma nova cidadania (p. 103-115). 


\section{SEMINÁRIO DE PESQUISA EM CIÊNCIAS HUMANAS - SEPECH \\ Humanidades, Estado e desafios didático-científicos \\ Londrina, 27 a 29 de julho de 2016}

GENRO, Tarso. Conselho de Desenvolvimento Econômico e Social: por um novo contrato social no Brasil. In: Governo e Sociedade Civil: um debate sobre espaços públicos democráticos. São Paulo, Ed. Petrópolis, ABONG, 2003.

IAMAMOTO, M. V. O serviço social na contemporaneidade: trabalho e formação profissional. São Paulo: Cortez, 1998.

- Serviço Social em tempo de capital fetiche: capital financeiro, trabalho e questão social. São Paulo: Cortez, 2010.

IAMAMOTO, M. V. \& CARVALHO, R. de. Parte I: Proposta de interpretação histórico-metodológica. Cap. II - O Serviço Social no processo de reprodução das relações sociais (p. 71-123). In: Relações sociais e Serviço Social no Brasil: esboço de uma interpretação histórico-sociológica. 10ª edição. São Paulo: Cortez/CELATS, 1995.

LOPES, Márcia Helena Carvalho. $\mathrm{O}$ tempo do SUAS. In: Revista Serviço Social e Sociedade, No 87, Cortez Editora, Ano XXVI, 2006.

OLIVEIRA, H. M. J. de. Cultura política e assistência social: uma análise das orientações de gestores estaduais. São Paulo: Cortez, 2003.

RAICHELIS, Raquel. Esfera Política e Conselhos de Assistência Social. Cortez, 2011. SPOSATI, A \& LOBO, E. Controle social e políticas de saúde. Cad. Saúde Pública. Rio de Janeiro, 8 (4):366-378, out/dez, 1992. 